\title{
Small-Cell Neuroendocrine Carcinoma of the Cervix Masquerading as a Cervical Fibroid Report of a rare entity
}

Mukta Pujani, ${ }_{1}^{1}$ Kanika Singh, ${ }^{1}$ "Varsha Chauhan, ${ }^{1}$ Raina Chawla, ${ }^{2}$ Rashmi Ahuja ${ }^{2}$

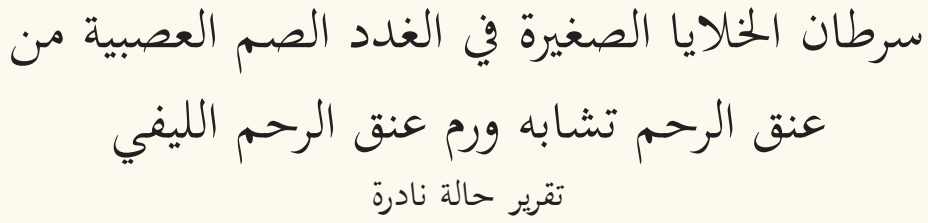

موكتا بوجاني، كانيكا سينغ، فـارشا تشوهان، رينا تشاولا، راشمي أهوجا

ABSTRACT: Primary neuroendocrine tumours of the cervix are extremely rare, with an incidence of only $0.5-1 \%$; as such, these entities can present a clinical and diagnostic challenge. Small-cell neuroendocrine carcinomas of the cervix are highly aggressive tumours that have a tendency to metastasise. We report a 44-year-old woman who presented to the Gynaecology Clinic of the Employees State Insurance Corporation Medical College \& Hospital, Faridabad, India, in 2016 with menorrhagia. Based on a clinical examination, she was provisionally diagnosed with a cervical fibroid. However, a biopsy revealed features of a small-cell neuroendocrine carcinoma of the cervix which was subsequently confirmed via immunohistochemistry. An accurate diagnosis of a neuroendocrine carcinoma is vital as it forms the basis for treatment decisions as well as informing predictions for long-term survival.

Keywords: Neuroendocrine Tumors; Small Cell Carcinoma; Cervix; Menorrhagia; Fibroid Tumor; Case Report; India.

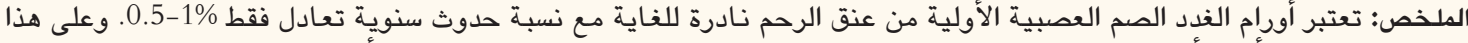

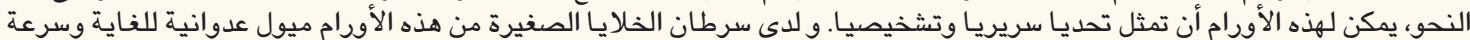

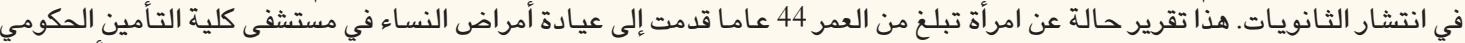

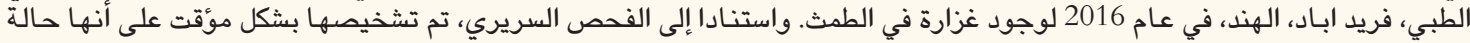

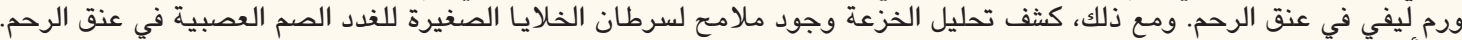

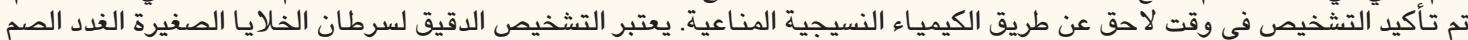



الكلمات المفتاحية؛ أورام الغدد الصم العصبية؛ سرطان الخلايا الصغيرة؛ عنق الرحم؛ غزارة الطمث؛ ورم ليفي؛ تقرير حالة؛ الهند.

$\mathrm{P}$ RIMARY NEUROENDOCRINE TUMOURS (NETS) of the female genital tract are extremely rare; among these, only $0.5-1 \%$ are cervical. ${ }^{1} \mathrm{~A}$ smallcell neuroendocrine carcinoma (SNEC) of the cervix is a poorly differentiated and highly aggressive tumour with a high metastatic propensity. ${ }^{2}$ On account of its dismal prognosis, an early diagnosis of this entity is crucial in order to differentiate it from other smallcell tumours of the cervix. ${ }^{3}$ Although histopathology remains the mainstay of diagnosis, immunohistochemistry (IHC) also plays a crucial role to both confirm the diagnosis as well as ascertain the primary site of origin of the tumour. ${ }^{2,3}$

\section{Case Report}

A 44-year-old woman presented to the Gynaecology Clinic of the Employees State Insurance Corporation
Medical College \& Hospital, Faridabad, India, in 2016 with a six-month history of menorrhagia. She had had four children and her last birth had taken place 15 years previously. A speculum examination revealed a globular well-defined mass of approximately $4 \mathrm{~cm}$ which was projecting from the posterior wall of the cervix. Upon physical contact, the mass did not bleed and did not appear ulcerative or fungating. An ultrasound indicated a $3.6 \mathrm{~cm}$ hypoechoic area in the upper part of the cervical canal, just below the internal orifice of the cervix uteri. During examination under anaesthesia, a $4 \times 3 \mathrm{~cm}$ well-defined mass was seen in the posterior wall of the cervix and was provisionally diagnosed as a fibroid.

A cervical biopsy was performed. Microscopic sections showed strips of stratified squamous epithelium, of which a few showed dysplasia. The underlying tissues exhibited sheets of tumour cells with erythro- 


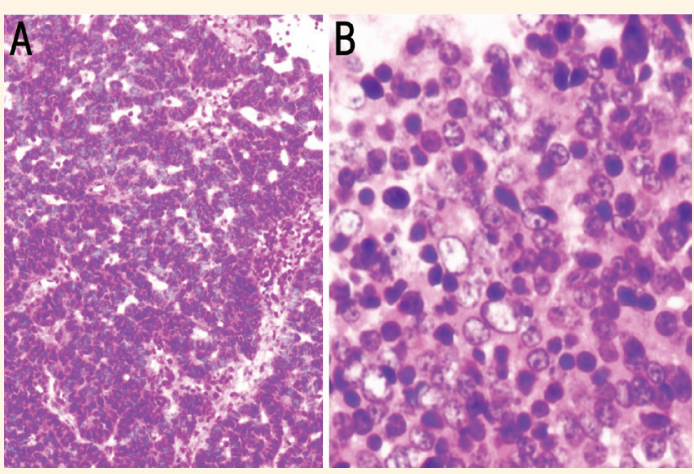

Figure 1: Haematoxylin and eosin stains at (A) x100 magnification showing sheets of tumour cells displaying erythrocyte rosetting and (B) at x400 magnification showing small round tumour cells with a high nuclearcytoplasmic ratio and stippled chromatin.

cyte rosetting in many places [Figure 1A]. The tumour cells were small and round, with a high nuclear-cytoplasmic ratio and stippled chromatin [Figure 1B]. The mitotic rate was very high at $>10$ mitoses/10 high power fields (HPFs). The surrounding stroma showed a dense inflammatory infiltrate and many areas of haemorrhage and necrosis. These histopathological features were consistent with a diagnosis of a SNEC of the cervix. This was confirmed by an IHC panel revealing strong positivity for synaptophysin, chromogranin, pan cytokeratin and p16 [Figure 2]. Neuronspecific enolase (NSE) was focally positive while stains for cluster of differentiation (CD)56 and thyroid transcription factor (TTF)-1 were negative.

Magnetic resonance imaging showed a large illdefined mass in the posterior wall of the cervix, indenting the cervical canal anteriorly. Fluorine-18-fluorodeoxyglucose positron emission tomography (PET)/computed tomography (CT) scans revealed a large, lobul-

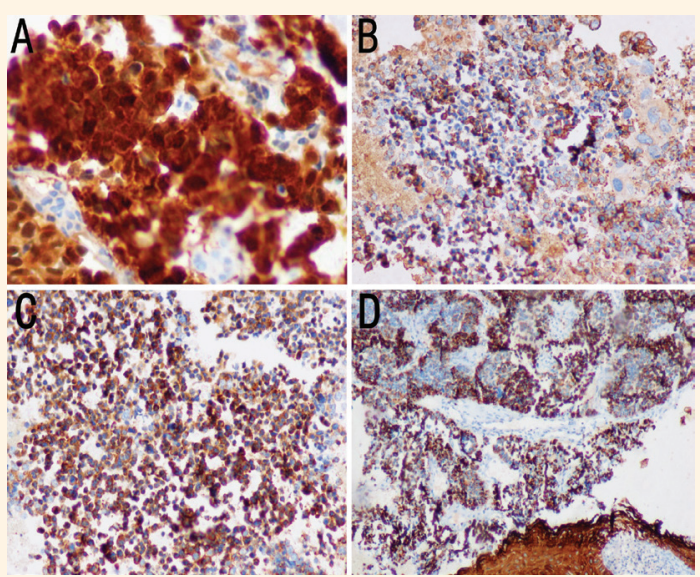

Figure 2: Immunohistochemistry photomicrographs showing strong positivity for (A) p16 at x400 magnification, (B) chromogranin at x100 magnification, (C) synaptophysin at X100 magnification and (D) pan cytokeratin at x100 magnification.

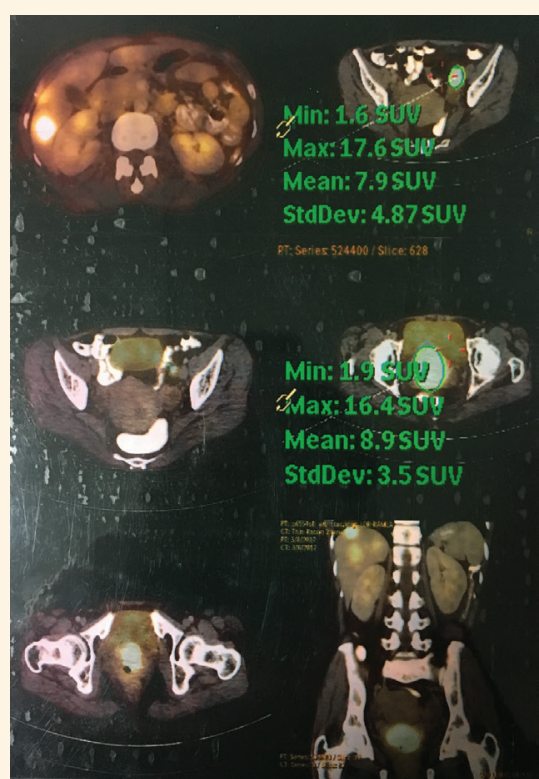

Figure 3: Serial fluorine-18-fluorodeoxyglucose positron emission tomography/computed tomography scans of a 44-year-old woman with a suspected cervical fibroid showing a large lobulated hypermetabolic mass involving the cervix and lower uterine segment. The mass is seen to invade the urinary bladder and rectum with multiple hypermetabolic hypodense lesions in both lobes of the liver.

ated, hypermetabolic lesion involving the cervix and lower uterine segment, with likely invasion of the vaginal vault and parametrial extension. The mass appeared to invade the urinary bladder and rectum. Multiple hypermetabolic hypodense lesions were present on both lobes of the liver, suggestive of metastasis [Figure 3]. The patient was diagnosed with a stage IVA SNEC of the cervix. She subsequently underwent six cycles of chemotherapy, including cisplatin and etoposide. A follow-up PET/CT scan suggested a partial response to treatment, with a residual metabolically-active primary malignant endocervical lesion as well as metastatic left external iliac lymph node and bilobar hepatic parenchymal lesions. There was no evidence of any other new lesions.

\section{Discussion}

On account of their rarity, primary NETs pose a clinical and diagnostic challenge., ${ }^{1,2}$ Moreover, an accurate diagnosis is vital as it forms the basis for treatment decisions as well as for predicting long-term survival. According to the latest WHO classifications, cervical neuroendocrine carcinomas are classified, similarly to gastroenteropancreatic neuroendocrine carcinomas, into grade 1, grade 2 or grade 3 NETs and into largecell or small-cell variants. ${ }^{4,5}$ In general, SNECs most commonly occur in the cervix, with patients ranging 
in age from $22-87$ years old and usually presenting with vaginal bleeding. Occasionally, patients may present with manifestations of paraneoplastic syndromes like syndrome of inappropriate anti-diuretic hormone secretion or Cushing's disease. ${ }^{2,3}$

Microscopically, the tumour cells of well-differentiated NETs are characteristically arranged in organoid, solid, nested, trabecular, insular or mixed patterns. ${ }^{2}$ Cells are typically small with a high nuclearcytoplasmic ratio, round-to-oval nuclei, nuclear moulding and salt-and-pepper chromatin, with scant-tomoderate eosinophilic cytoplasm. However, poorlydifferentiated neuroendocrine carcinomas-including both small- and large-cell types-have high mitotic activity (>10 mitoses/10 HPFs), necrosis and are highgrade malignancies. ${ }^{2}$ Human papillomavirus (HPV) infections have been associated with $90 \%$ of cases of SNEC of the cervix, with HPV type 18 most commonly implicated. ${ }^{6}$ Small-cell variants are also characterised by lymphovascular invasion. Small foci of squamous and/or glandular differentiation can be seen, but usually account for less than $5-10 \%$ of the total volume of the tumour. ${ }^{2}$

Although histopathology remains the gold standard for diagnosing neuroendocrine carcinomas in most cases, IHC is usually required to establish the neuroendocrinological nature of the tumour, confirm the diagnosis and provide prognostic information. ${ }^{4}$ In the current case, the typical morphological features of a neuroendocrine carcinoma were evident on histopathology sections, with IHC playing a supplementary role. The IHC panel for a neuroendocrine carcinoma includes NSE, chromogranin, synaptophysin, CD56 and synaptic vesicle protein $2 .^{2,4}$ As not all markers are specific, an integrated IHC panel of three to four markers should be used; of these, chromogranin, synaptophysin and CD56 are most commonly applied. ${ }^{7,8}$ In a large series of 45 patients, Ganesan et al. found synaptophysin to be the most specific and sensitive marker of neuroendocrine differentiation. ${ }^{3}$ In addition, NETs usually express pan cytokeratin, as in the present case. ${ }^{2}$ Various IHC markers may also help to ascertain the primary site of an NET, for example TTF-1 (the thyroid and lungs), insulin gene enhancer protein-1 and insulin promoter factor 1 (the pancreas) and caudal type homeobox 2 and villin (the gastrointestinal tract). ${ }^{2}$ However, TTF-1 may also be positive in neuroendocrine carcinomas of cervical origin. ${ }^{3}$ Although no specific marker is documented for NETs of the female genital tract, p16 positivity is commonly found, as in the present case. ${ }^{2}$

The differential diagnosis of small-blue-cell cervical tumours include basaloid squamous cell carcinomas, embryonal rhabdomyosarcomas, lymphomas and un- differentiated carcinomas. ${ }^{2}$ Due to the rarity of SNECs of the cervix, it is important to exclude metastasis from the lung. ${ }^{3}$ As cervical fibroids can present clinically as a carcinoma or prolapse, cervical carcinomas can sometimes be mistaken for fibroids, as in the present case., ${ }^{910}$ Seo et al. described a 46-year-old woman with metastatic breast cancer spreading to the cervix which initially appeared as a large cervical fibroid on sonography and was only diagnosed after treatment of the primary tumour. ${ }^{11}$ This may lead to grave consequences since fibroids are benign lesions which can be cured via surgical excision while carcinomas usually require a multimodal approach involving surgery, chemotherapy or radiotherapy, with prognosis dependent on the type and stage of the tumour. As such, the radiographical evaluation of suspected NETs should include CT or PET/CT scans. ${ }^{12}$

Various combined chemotherapy regimens have improved the median survival rate among patients with small-cell bronchogenic carcinomas and are now being used to treat SNECs of the cervix. ${ }^{13}$ Hoskins et al. reported the successful treatment of a stage IA-IVB cervical small-cell carcinoma using chemoradiation with etoposide and cisplatin. ${ }^{14}$ Notably, such regimens are generally preferred over those containing vincristine, adriamycin and cyclophosphamide as they are less toxic. Surgical resection is usually undertaken for limited-stage neuroendocrine carcinomas. The use of platinum with or without etoposide has also been observed to improve survival in SNEC cases. ${ }^{14}$ An advanced stage, tumour size, the presence of lymph node metastasis, pure small-cell histology and smoking are associated with worse clinical outcomes for patients with SNECs. ${ }^{15}$

\section{Conclusion}

Neuroendocrine carcinomas of the cervix, particularly small-cell variants, present a clinical and diagnostic challenge due to their rarity. Although histopathology remains the gold standard for diagnosing neuroendocrine carcinomas, IHC is usually required to confirm the diagnosis as well as to inform treatment decisions and provide prognostic information. This case highlights that the clinical presentation of SNECs can, on rare occasions, be mistaken with that of a cervical fibroid.

\section{References}

1. Chen J, Macdonald OK, Gaffney DK. Incidence, mortality, and prognostic factors of small cell carcinoma of the cervix. Obstet Gynecol 2008; 111:1394-402. doi: 10.1097/AOG.0b013e31817 $3570 \mathrm{~b}$. 
2. Kefeli M, Usubütün A. An update of neuroendocrine tumors of the female reproductive system. Turk Patoloji Derg 2015; 31:S128-44. doi: 10.5146/tjpath.2015.01320.

3. Ganesan R, Hirschowitz L, Dawson P, Askew S, Pearmain P, Jones PW, et al. Neuroendocrine carcinoma of the cervix: Review of a series of cases and correlation with outcome. IntJSurg Pathol2016;24:490-6.doi:10.1177/1066896916643385.

4. Kurman RJ, Carcangiu ML, Herrington CS, Young RH, Eds WHO Classification of Tumours of Female Reproductive Organs, 4th ed. Lyon, France: IARC Press, 2014.

5. Bosman FT, Carneiro F, Hruban RH, Theise ND, Eds. WHO Classification of Tumours of the Digestive System, 4th ed. Lyon, France: IARC Press, 2010.

6. Stoler $\mathrm{MH}$, Mills SE, Gersell DJ, Walker AN. Small-cell neuroendocrine carcinoma of the cervix: A human papillomavirus type 18-associated cancer. Am J Surg Pathol 1991; 15:28-32. doi: 10.1097/00000478-199101000-00003.

7. Chu P, Weiss L. Tumors of the endocrine system. In: Modern Immunohistochemistry, 2nd ed. Cambridge, UK: Cambridge University Press, 2014. Pp. 96-132.

8. DeLellis RA. The neuroendocrine system and its tumors: An overview. Am J Clin Pathol 2001; 115:S5-16. doi: 10.1309/7GR5L7YW-3G78-LDJ6.

9. Harrison AO. Prolapsed giant cervical fibroid polyp mimicking procidentia: Aftermath of traditional therapy for fibroids - A case report and review of the literature. Open Sci J Clin Med $2014 ; 2: 15-18$
10. Sharma P, Swaroop N, Kumari K, Nagrath A. A case of giant cervical fibroid polyp prolapsed outside introitus in menopausal women: Presenting as diagnostic dilemma. J South Asian Fed Menopause Soc 2016; 4:47-9. doi: 10.5005/jp-journals10032-1084.

11. Seo SY, Shin JY, Ji YI. Metastatic uterine cancer looking as cervical fibroid in recurrent breast cancer woman: A case report. Obstet Gynecol Sci 2017; 60:481-4. doi: 10.4568/ogs.2017.60. 5.481

12. Baum RP, Swietasczyk C, Prasad V. FDG-PET/CT in lung cancer: An update. Front Radiat Ther Oncol 2010; 42:15-45. doi: $10.1159 / 000262458$

13. Nasu K, Hirakawa T, Okamoto M, Nishida M, Kyoshima C, Matsumoto $\mathrm{H}$, et al. Advanced small cell carcinoma of the uterine cervix treated by neoadjuvant chemotherapy with irinotecan and cisplatin followed by radical surgery. Rare Tumors 2011; 3:e6. doi: 10.4081/rt.2011.e6.

14. Hoskins PJ, Swenerton KD, Pike JA, Lim P, Aquino-Parsons C, Wong F, et al. Small-cell carcinoma of the cervix: Fourteen years of experience at a single institution using a combined-modality regimen of involved-field irradiation and platinum-based com-bination chemotherapy. J Clin Oncol 2003; 21:3495-501. doi: 10.1200/JCO.2003.01.501

15. Gardner GJ, Reidy-Lagunes D, Gehrig PA. Neuroendocrine tumors of the gynecologic tract: A Society of Gynecologic Oncology (SGO) clinical document. Gynecol Oncol 2011; 122:190-8. doi: 10.1016/j.ygyno.2011.04.011. 